\title{
USE OF BEHAVIOR MANAGEMENT STRATEGIES IN CHILDREN WITH AND WITHOUT DISABILITIES: A COMPARATIVE STUDY OF GREEK PARENTS' AND TEACHERS' OPINIONS
}

\author{
Pagona Leonidou', \& Lefkothea Kartasidou ${ }^{2}$ \\ ${ }^{1}$ Phd Student, Department of Educational and Social Policy, University of Macedonia (Greece) \\ ${ }^{2}$ Associate Professor, Department of Educational and Social Policy, University of Macedonia (Greece)
}

\begin{abstract}
Behavior problems either at school or at home are a great challenge for all people that are responsible for a child's upbringing and education, that is mainly parents and teachers. Teachers often encounter intense stress and discomfort about the classroom management. Moreover, family tranquility and balance are disrupted, since the behavior problems management on the parents' behalf causes stress and anxiety to all members. Thus, taking into account parents' and teachers' physical and psychological exhaustion in their everyday life, the use of positive discipline strategies seems to be a great challenge. The aim of the current study is the investigation of the similarities and differences in the use of behavior management strategies by teachers and parents, as they state them. The research questions were a) which strategies do parents most often use and which do teachers use? and b) do parents or teachers more often use positive discipline strategies? Participants, 110 parents and 200 teachers (of primary and secondary education), were randomly selected and came mostly from cities in Central and Northern Greece. The instruments used were the Teacher Classroom Management Strategies Questionnaire (TSQ: Webster-Stratton, 2002) and the Parent Practices Inventory-Interview Form (PPI: Webster - Stratton, 1998). The results show that, in general, Greek parents manage behavioral problems mostly by using positive verbal discipline strategies, while Greek teachers state that they mostly use coaching, praise and incentives and they, also, almost equally use proactive and SEL strategies, even though only $30 \%$ of them have applied a social and emotional learning program in their classroom. Concerning the second research question, teachers seem to use positive strategies more often than parents. The current study has important implications for the scientific field, as its results could form the basis of the design and implementation of a Social Emotional intervention or training program for teachers and parents, who constitute a basic factor in the management of a child's behavior problems.
\end{abstract}

Keywords: Teachers, parents, children with disability, behavior problems management.

\section{Introduction}

The role of the family in the child's social development is extremely important and may even be a risk factor or a protective factor, one of which is the way parental education. According to some researchers, there are three types of education: authoritarian, permissive or democratic (eg, Herbert, 2000), while others add to the neglected way of education (eg, the British Medical Association Board of Science, 2013). Equally important is the role of the school, in particular the teacher, in the social and emotional development of the students through the interactive relationships within the school. According to Glickman and Tamashiro (1980, 460), teachers' beliefs towards discipline on a continuum of control reflect the extent to which teachers want to exercise control on their students' behavior. So, teachers can be: interventionists, non-interventionists or interactionalists.

Several studies have been carried out to compare parents 'and teachers' views on what is a behavioral problem (eg, Phares, Compas, \& Howell, 1989) and their causes (eg, Snyder et al. 2005). In addition, for each group, investigations have been made on the use of a specific dimension of parental behavioral behavior management such as hard discipline (McKee, Roland, Coffelt, Olson, Forehand, Massari, Jones, Gaffney, and Zens, 2007) or for using teacher techniques (eg Tillery, Varjas, Meyers, \& Smith Collins, 2010). Also, in the context of Incredible Years Project surveys, there have been studies on the use of management techniques of the two groups before and after the corresponding training program (Fergusson, Horwood, \& Stanley, 2013; Rosanbalm \& Christopoulos, 2011). Therefore, the comparison of 
parents' and teachers' views on the behavioral management techniques they use is a research that has not been done so far and constitutes a matter of a great pedagogical research. Moreover, because of parents' and teachers' stress and fatigue, and often negative attitudes, positive behavioral support and the use of positive discipline strategies to tackle behavioral problems at home or at school are challenging and will be a research question for the current study.

\section{Objectives}

The aim of the current research is to investigate similarities and differences in the use of behavior management strategies by teachers and parents, as they state them. Specifically, to achieve this purpose, the following research questions were formulated:

a) Which strategies do parents most often use and which do teachers use?

b) Do parents or teachers more often use positive discipline strategies?

\section{Methodology}

\subsection{Participants}

Two separate surveys were conducted, so that conclusions would be extracted concerning the use of behavior management strategies used by teachers and parents, as they state them. Participants in the first survey (Leonidou \& Kartasidou, 2016) were teachers from schools in Central and North Greece, mostly working in primary than secondary education. There were 146 women (73\%) and 54 men (27\%) in various ages ranging from 23 to 59 ages with $47.8 \%$ of teachers at the age range 44-54, 25.3 at the age range $20-34,18.3 \%$ between 35 and 44 and last $8.6 \%$ of the teachers aged 55 or older. There were 98 special educators $(36.5 \%$ of whom were working in special primary schools, $11.5 \%$ in integrative classes and $1 \%$ in parallel support) and 102 general educators (51\%). In a question posed to them about whether they have ever implemented a Social Emotional Learning (SEL) program only 31\% answered positively.

Participants in the second survey (Leonidou \& Kartasidou, 2018) were 110 parents /caregivers from Central (31,5\%), North (57,7\%), South Greece (5,4\%) and greek islands $(5,4 \%)$. Mostly mothers $(83,8 \%)$ completed the questionnaire and only $12,6 \%$ fathers and 3,6\% guardians, who are authorized to act as the child's parent (in the current study, the term parents will include both biological parents and guardians of a child).

\subsection{Procedure-Analysis}

The survey concerning teachers was conducted during school years 2013-14 and 2014-15, after a personal contact with the participants in order to inform them about the aim of the survey. The second survey, concerning parents, was conducted during school years 2015-16 and 2016-17 after a written contact with the participants to inform them about the aim of the survey. The questionnaires were anonymously completed either in written form or in google form available online by the researchers. The answers were analyzed separately with the statistical package of SPSS 20.0 and 24.0 respectively. Finally, results of similar sections of the two instruments were compared, so as to draw conclusions concerning the research questions.

\subsection{Instrumentation}

Two different instruments were utilized for the collection of information. The Copyright of the istruments belongs to the Incredible Years project (IY), which is a series of interlocking, evidence-based programs for parents, children, and teachers, supported by over 30 years of research by Webster-Stratton and her scientific team. Their goal is to prevent and treat young children's behavior problems and promote their social, emotional, and academic competence. The programs are used worldwide in schools and mental health centers, and have been shown to work across cultures and socioeconomic groups (http://www.incredibleyears.com/). Indeed, Incredible Years project is listed as a validated, evidence-based program by many organizations, as stated in the official project's website (http://www.incredibleyears.com/about/awards-and-recognition/). Both instruments were translated in greek with the back-translation method after written permission from and in cooperation with the Incredible Years project's Administrative manager. Only some, mainly, linguistic changes were made, such as adding articles, because in Greek they cannot always be missed out (Leonidou, \& Kartasidou, in press). The scoring directions for both instruments were retrieved from the IY program's official page (http://incredibleyears.com/for-researchers/measures/).

Teachers anonymously completed the Incredible Years (IY) Teacher Classroom Management Strategies Questionnaire (TSQ: Webster-Stratton, 2012), which consists of four sections: A, B, C and D. These sections were: A. Teacher's confidence in managing current and future behavior problems and 
confidence in promoting emotional, social and problem solving teaching, B. frequency of use and usefulness of five categories of teaching strategies [(Coaching, Praise and Incentives ( 8 items), Proactive strategies (8 items), Social \& Emotional teaching strategies (7 items), Limit-setting strategies (5 items), and Inappropriate strategies ( 9 items)], C. frequency of use and usefulness of positive approaches with parents and, last, D. planning and support related strategies. The answers are offered on a 5-point Likert scale, ranging from: 1- rarely/never, to 5- very often to measure the frequency of use and the usefulness. For achieving the objectives of the current study only Section B measuring the frequency of use of strategies was administered to the participants.

Parents anonymously completed the Parent Practices Interview (PPI: Webster-Stratton, 1998). It is a 72-item questionnaire adapted from the Oregon Social Learning Center's Discipline Questionnaire and revised for young children. It is composed of seven subscales: a) Appropriate Discipline (12 items), b) Harsh and Inconsistent Discipline (15 items), c) Positive Verbal Discipline (9 items), d) Monitoring (5 items), e) Physical Punishment (6 items), f) Praise and Incentives (11 items) and g) Clear Expectations (6 items). The items in each section are offered on Likert scales, different for each section e.g. ranging from: 1-"Never" to 7-"Always" or from 1-"None or almost none" to 5-"All or almost all" e.t.c. depending on the type of question.

\subsection{Reliability}

The reliability of the scales of classroom management strategies utilized for the teachers' study, as measured with Cronbach's Alpha are: .737 for Coaching, Praise and Incentives, .740 for Proactive strategies, .828 for Social and Emotional Teaching strategies, and .594 for Inappropriate strategies. The reliability score for the whole section of Specific teaching techniques is .941. The reliability of the scales of parents' management strategies for the present study also measured with Cronbach's Alpha are: .762 for Appropriate Discipline, .846 for Harsh and Inconsistent Discipline, .276 for Positive Verbal Discipline, .568 for Praise and Incentives. The reliability score for the whole questionnaire, also measured with Cronbach's Alpha, is .739.

\section{Results}

Even though the use of different instrument for each group of participants does not allow for a direct comparison of means, still there can be a comparative presentation of the results in order to extract some results concerning the research questions. Only answers to certain parts of each questionnaire were exploited, which were thought to be relevant to both groups of participants and therefore comparable. For example, questions about physical punishment were extracted from the parents' questionnaire as irrelevant to teachers and in the same way questions about planning of teaching and support were extracted from the teachers' questionnaire as irrelevant to parents.

In the teachers' survey, in a scale ranging from 1-5 the mean frequency of use of coaching, praise and incentives is 3.6885, the mean frequency of use of proactive strategies is 3.5437 and SEL strategies' mean frequency of use is 3.5327. Frequency of use of inappropriate strategies demonstrated a relatively low mean ( $\mathrm{M}=2.2649)$. According to parents' statements, in a scale ranging from $1-7$, they state that they mostly use Positive Verbal Discipline $(\mathrm{M}=4.98)$ and Praise and Incentives $(\mathrm{M}=4.08)$, Appropriate Discipline strategies (M=3.73), and least of all Harsh and Inappropriate Discipline strategies (M=3.00).

On the individual item level for teachers, the least used $(M=1.12)$ technique was considered to be 'sending child home' for aggressive or destructive misbehavior, while 'praising positive behavior' was considered/deemed the most frequently used one $(\mathrm{M}=4.68)$. At the level of individual items, in the parents' survey, regarding the subscale Positive Verbal Discipline, the most preferred technique seems to be "discussing the problem with the child or asking questions, in case of their child hitting another child" $(M=6.29)$ and the least preferred technique is praising children when they do well $(M=2.64)$. In the subscale Praise and Incentives, when the child behaves well or does a good job, parents state that they quite often give their child a hug, kiss, pat, handshake or "high five" $(\mathrm{M}=6.52)$, and the least used technique on the same occasion is giving points or stars on a chart $(\mathrm{M}=2.41)$. Regarding the subscale Appropriate Discipline, parents state that when their child fights, steals or lies, they will most likely punish their child (M=5.64) and they would least likely have the child correct the problem or make up for his/her mistake in case of non-compliance (M.=1.85). In the subscale Harsh and Inconsistent Discipline, Greek parents state that if their child hit another child, they would most probably raise their voice, scold or yell $(\mathrm{M}=4.12)$ and they would least likely ignore their non-compliance $(\mathrm{M}=2.08)$.

In addition, for teachers, T-tests and one-way Anova tests revealed statistical significance $(p<0.005)$ between the two genders on the item concerning frequency of use of reward targeting positive behaviors with incentives, e.g., stickers, with women $(\mathrm{M}=4.29)$ using it more often than men $(\mathrm{M}=3.57)$. For parents, no statistically significant differences were revealed between genders. 


\section{Discussion}

The results of the present research were examined in comparison with results in other countries since, to the best of our knowledge, this is the first study in Greece that examines parents' and teachers' management strategies of their children's behavioral problems.

Regarding the first research question about "which strategies parents more often use and which teachers use", according to the current study, Greek parents state that they mostly use Positive Verbal Discipline strategies. This result is not consistent with previous studies of Harman and Blair (2016) in North Carolina, U.S.A., according to which parents manage behavior problems by stating Clear Expectations or another study in Colorado, U.S.A., the results of which showed that parents mostly use Monitoring strategies (OMNI, 2011). This difference could be explained in terms of different cultural contexts or even different methodological choices in each study (Leonidou \& Kartasidou, in press). Unfortunately, no similar research has been conducted in Greece, so that the results could be compared within the same cultural context.

As far as Greek teachers are concerned, they state that they prefer using coaching, praise and incentives and the result is confirmed by their preference to the technique "praising positive behavior", which is stated to be the most useful and most frequently used one (Leonidou \& Kartasidou, 2016). In Greece, research by Andreadakis, Xanthakou and Kandianaki (2006) shows that teachers assume responsibility for creating a positive communication climate in the classroom as they accept that their behavior can either facilitate or undermine the creation of a learning-oriented communication climate. According to modern pedagogical approaches teaching is approached in terms of active participation, meaningful negotiation, interaction, effective communication, development of pupils' self-esteem, and can be facilitated by the development of interpersonal relationships. All these concepts are in line of course with the concepts of Social Emotional Learning, according to which the positive classroom climate promotes students' emotional and academic development. In that sense, possibly Greek teachers use praise and incentives as a means to achieve the development of interpersonal relationships and the positive climate in their classroom along with the academic gains.

Concerning the second research question if Greek parents or teachers more often use positive discipline strategies, it seems that teachers seem to prefer using positive ones rather than inappropriate, which are only used sometimes according to the mean scores indicated. That is because they consider positive strategies very important in classroom management, which is in line with previous research studies such as the one by Arbuckle and Little (2004). Moreover, parents state that, overall, they quite often use Positive Discipline strategies, either in the form of Positive Verbal Discipline or Praise and Incentives and they least of all use Harsh and Inappropriate Discipline strategies. Preference for positive methods of discipline is particularly encouraging, as it is scientifically proven that a child-centered parenting style, high levels of positive family relationships and warmth, parental supervision, rule-setting and positive reinforcement of appropriate behaviors are associated with fewer behavioral problems, increased self-confidence, better academic performance and cognitive development (Hutchings, Bywater, Daley, Gardner, Whitaker, Jones, Eames, \& Edwards, 2007). These results allow us to think that teachers and parents almost equally use positive strategies in general in different forms, for example teachers use praise and incentives, while parents use positive verbal discipline strategies, mainly discussing the problem with the child.

However, to a lesser extent, but both teachers and parents use Harsh or Inconsistent Discipline strategies. Parenting practices that have been found to have negative effects on emotional and behavioral adaptation include tough and inconsistent discipline, high levels of criticism, poor supervision, poor child care and lack of warmth in parent-child interaction (Patterson, Baryshe, \& Ramsey, 1989). Teachers also state that they often use prevention and limit setting strategies, such as discipline plan, clear rules etc, because they consider them important, as it was also concluded in previous research studies (e.g. Dutton Tillery, Varjas, Meyers, \& Smith Collins, 2010). Therefore, there seems to be room for improvement for both groups of participants, possibly by participating in behavior management trainings.

In conclusion, these results are hopeful, of course, since the whole school philosophy has started changing and the aim is no longer to burden students with loads of knowledge, but to engage them in developing as a whole person with mind, heart and soul, and parents could surely help since education and even more character education starts at home. In addition, even though both groups of participants state that they prefer positive strategies, still there seems to be a need for further training so that negative strategies would no longer be needed. 


\section{References}

Andreadakis, N., Xanthakou, G., \& Kandianaki, M. (2006). Empeirike melete tou epikoinoniakou plaisiou tes scholikes taxes. [Empirical study of the communication framework of the classroom]. In Ch.. Papailiou, G. Xanthakou, \& S. Chatzicristou (E $\pi \mu$.), Ekpaideutiké scholiké psychología [Educational School Psychology]. Athens: Atrapos.

Arbuckle, C. \& Little, E. (2004). Teachers' Perceptions and Management of Disruptive Classroom Behaviour during the Middle Years (years five to nine). Australian Journal of Educational and Developmental Psychology, 4, 59-70.

Dutton Tillery, A., Varjas, K., Meyers, J. \& Smith Collins, A. (2010). General Education Teachers' Perceptions of Behavior Management and Intervention Strategies. Journal of Positive Behavior Interventions, 12(2), 86-102.

Fergusson, D., Horwood, L.J., \& Stanley, L. (2013). A preliminary Evaluation of the Incredible Years Teacher Programme. New Zealand Journal of Psychology, 42(1), 77-82.

Glickman, C.D., \& Tamashiro, R.T. (1980). Clarifying teachers' beliefs about discipline. Educational Leadership, 37, 459-464.

Harman, A., \& Blair, R. (2016). The Incredible Years Preschool and School Age BASIC Parent Series FY 2015-2016, North Carolina Outcomes Evaluation, Executive summary prepared for Prevent Child Abuse North Carolina. Retrieved December 13, 2018 from https://www.preventchildabusenc.org/images/IY_1516_State_Final_Report.pdf

Hutchings, J., Bywater, T., Daley, D., Gardner, F., Whitaker, C., Jones, K., Eames, C., \& Edwards, R. (2007). Parenting Intervention in Sure Start Services for Children at Risk of Developing Conduct Disorder: Pragmatic Randomized Controlled Trial. BMJ: British Medical Journal, 334, 678-685.

Leonidou, P. \& Kartasidou, L. (in press). Management of behavior problems of children with and without disabilities: Towards Parental Training and Intervention Programs in Greece. In M. Carmo, WIARS, (Eds.), Education Applications \& Developments IV, Portugal, inScience Press.

Leonidou, P. \& Kartasidou, L. (2018). Management of behavior problems of children with and without disabilities: Greek parents' opinions. Proceedings of International Conference on Education and New Developments END 2018, Budapest, 23-25 June, 189-193, ISBN: 978-989-99864-8-0.

Leonidou, P. \& Kartasidou, L. (2016). Management of behavior problems of students with disabilities: Greek teachers' opinions. Proceedings of International Conference on Education and New Developments END2016, Ljubljana, 12-14 June, 324-328. ISBN: 978-989-99389-8-4.

McGilloway, S., Hyland, L., Ní Mháille, G., Lodge, A., O’Neill, D., Kelly, P., Leckey, Y., Bywater, T., Comiskey, C. \& Donnelly, M. (2011). Positive classrooms, Positive children: A randomised controlled trial to investigate the effectiveness of the Incredible Years Teacher Classroom Management Programme in an Irish context (short-term outcomes), Ireland: Archways.

McKee, L., Roland, E., Coffelt, N., Olson, A.L., Forehand, R., Massari, C., Jones, D., Gaffney, C. \& Zens M.S. (2007). Harsh discipline and child problem behaviors: The roles of positive parenting and gender. Journal of Family Violence, 22(4), 187-196.

OMNI Institute, (2011). Evaluation of The Incredible Years: September 2010 - August 2011. Retrieved from http://www.socialimpactexchange.org/sites/www.socialimpactexchange.org/files/2010$2011 \% 20 I Y \% 20$ Executive\%20Summary.pdf on 12/24/2018.

Patterson, G.R., DeBaryshe, D., \& Ramsey, E. (1989). A developmental perspective on antisocial behavior. American Psychologist, 44(2), 329-335.

Phares, V., Compas, B. E., \& Howell, D. C. (1989). Perspectives on child behavior problems: Comparisons of children's self-reports with parent and teacher reports. Psychological Assessment: A Journal of Consulting and Clinical Psychology, 1(1), 68-71.

Rosanbalm, K., \& Christopoulos, C. (2011). Incredible Years: Expected Effects and Recommendations for Monitoring Outcomes. Brief commissioned by the Duke Endowment.

Snyder, J., Cramer, A., Afrank, J., \& Patterson, G. (2005). The Contributions of Ineffective Discipline and Parental Hostile Attributions of Child Misbehavior to the Development of Conduct Problems at Home and School. Developmental Psychology, 41(1), 30-41.

Webster-Stratton, C. (1998a). Preventing Conduct Problems in Head Start Children: Strengthening Parenting Competencies. Journal of Consulting and Clinical Psychology, 66(5), 715-730.

Webster-Stratton, C. (1998b). Parent Practices Inventory-Interview Form (American version). Retrieved from http://www.incredibleyears.com/Measures/forms/PPI-parenting-practices-interview-form.pdf on $9 / 20 / 2012$.

Webster-Stratton, C. (1998c). Parent Practices Inventory-Scoring Guide. Retrieved from $\mathrm{http} / / /$ incredibleyears.com/for-researchers/measures on 9/20/2012.

Webster-Stratton, C. (2012). Teacher Strategies Questionnaire (american version). Retrieved from http://incredibleyears.com/for-researchers/measures/ on 9/20/2012. 